$\begin{array}{ll} & \text { Etnográfica } \\ \text { etnográfica } & \text { Revista do Centro em Rede de Investigação em }\end{array}$

Antropologia

vol. $16(1) \mid 2012$

Vol. $16(1)$

\title{
Os usos da narrativa futebolística portuguesa em Maputo
}

The uses of the Portuguese football narrative in Maputo

\section{Nuno Domingos}

\section{(2) OpenEdition}

\section{Journals}

\section{Edição electrónica}

URL: https://journals.openedition.org/etnografica/1432

DOI: 10.4000/etnografica. 1432

ISSN: 2182-2891

\section{Editora}

Centro em Rede de Investigação em Antropologia

\section{Edição impressa}

Data de publição: 1 fevereiro 2012

Paginação: 163-183

ISSN: 0873-6561

\section{Refêrencia eletrónica}

Nuno Domingos, «Os usos da narrativa futebolística portuguesa em Maputo», Etnográfica [Online], vol. 16 (1) | 2012, posto online no dia 06 março 2012, consultado o 12 fevereiro 2022. URL: http:// journals.openedition.org/etnografica/1432 ; DOI: https://doi.org/10.4000/etnografica.1432

\section{(c) (7) (8)}

Etnográfica is licensed under a Creative Commons Attribution-NonCommercial 4.0 International License. 


\section{Os usos da narrativa futebolística portuguesa em Maputo}

Nuno Domingos

Este artigo investiga os usos sociais do que aqui designamos por "narrativa futebolística portuguesa" na cidade de Maputo. Procurar-se-á interpretar a relação dos portugueses na capital moçambicana com esta narrativa, questionando a ligação automática estabelecida muitas vezes entre o consumo específico do futebol, tido como uma característica da cultura nacional, e a existência de uma comunidade portuguesa, cuja representação, como um todo relativamente homogéneo, acaba por reificar os desígnios de uma história nacional. No caso de Maputo, no entanto, o estudo da presença do futebol português tem o interesse suplementar de não se limitar a confrontar os discursos homogeneizadores de comunidades nacionais, mas também questionar essa comunidade plurinacional, dita lusófona, que junta um conjunto de países pretensamente unidos por uma herança cultural.

PALAVRAS-CHAVE: futebol, lazer, narrativas, rituais sociais, comunidades, colonialismo.

The uses of the Portuguese football narrative in Maputo - This article researches the social uses in Maputo of what is here called the "narrative of Portuguese football". The relation between the Portuguese populations in the capital of Mozambique with this narrative will be interpreted as a critical exam of the connection made between football as a particular consumption, taken as a characteristic of the national culture, and the existence of a Portuguese community. Represented as a homogenised whole this community reifies the logic of a national history. In Maputo's case, however, the study of Portuguese football allows not only to confront the homogenising discourse on national communities but also to question that transnational community called lusophone, which gathers a group of countries supposedly united by a cultural heritage.

KEYWORDS: football, leisure, narratives, social rituals, communities, colonialism.

DOMINGOS, Nuno (nuno.domingos@ics.ul.pt) - Instituto de Ciências Sociais da Universidade de Lisboa, Portugal; Soas' Food Studies Centre, University of London, Reino Unido. 
ESTE TRABALHO RESULTA DE UMA COLEÇÃO DE MOMENTOS ETNOGRÁficos que, dado o seu caráter esparso, é neste artigo apresentada de forma sintética e em diálogo com dados de outra natureza. A observação decorreu durante dois períodos, em 2006 e 2008. Neste segundo período, a pesquisa etnográfica foi coordenada no terreno por Nuno Barbosa, a quem devo um agradecimento especial. Este artigo, ao contrário de outros presentes neste dossiê, centra-se no consumo do desporto enquanto elemento de uma cultura popular urbana e não na sua prática.

\section{ESTUDAR O FUTEBOL E A EMIGRAÇÃO}

O estudo da relação entre futebol e emigração pode ser interpretado como uma continuidade da análise da relação entre futebol e nação. Inúmeros estudos têm prosseguido esta linha de inquérito, exemplificando as formas como o futebol tem acentuado e reproduzido identidades nacionais. ${ }^{1}$ Neste sentido, os emigrantes, representando uma espécie de nação em movimento, seriam portadores dos traços que identificam uma cultura nacional, distinta das outras culturas com que se relacionam nos países de acolhimento. O consumo do futebol do país de origem tem o potencial de surgir como mais uma marca da singularidade nacional, confirmando este laço como elemento matricial das vidas de um grupo de indivíduos, agregados em "comunidade". O futebol, como mecanismo de identificação e representação, encontrar-se-ia ao lado de outro conjunto de referentes "culturais", onde se incluem aspetos tão diversos como a tradição gastronómica, a reprodução de uma cultura popular tradicional, a comemoração de dias festivos ou a constituição de associações de índole nacional ou regional.

O domínio daquilo que designo por "narrativas futebolísticas" confere a possibilidade de representação de entidades definidas nacional, regional ou localmente. A relação destas narrativas com a sociedade e a história encontra-se para além, no entanto, das fronteiras que delimitam esta função de reforço identitário. ${ }^{2}$ Norbert Elias, ao enunciar a existência de um processo de desportivização (Elias 1992: 192), estabeleceu uma ligação causal entre o advento das práticas desportivas modernas e um conjunto de transformações estruturais: o crescimento da divisão social do trabalho, do qual decorria determinada estratificação social, o incremento da centralização do Estado, o aumento das interdependências sociais e, por fim, o surgimento de práticas de lazer, transformadas na substância de culturas populares urbanas em processo

I Ver, entre outros, MacClancy (1996), Bale e Cronin (2003), Armstrong e Giulianotti (1999, 2001, 2004) e Mangan e Ritchie (2004).

2 A expressão "narrativas futebolísticas" foi também utilizada em Domingos e Kumar (2006) e Domingos (2009). 
de generalização. A conjugação destes elementos explicaria a emergência de desportos modernos com regras codificadas e universais que proporcionariam o encontro entre equipas de diferentes proveniências.

A aptidão representativa das narrativas futebolísticas, como meio público e de simbolizar entidades diversas, concorre para ocultar a diversificação das suas funções e usos estratégicos. Para compreender estes usos é fundamental considerar estas narrativas como uma "forma social" própria, meio de organização de um stock de conhecimento social (Berger e Luckman 1967: 41) específico, acumulado por grupos de indivíduos de acordo com as particularidades do seu percurso e padrões de socialização. Em termos genéricos, por exemplo, este conhecimento específico tem sido acumulado e reproduzido mais por homens do que por mulheres. Em determinados contextos, as narrativas atravessam com facilidade as fronteiras que definem uma estrutura de classes, noutros, são marcadamente reproduzidas por estratos da população socialmente localizados. Uma das características deste stock de conhecimento social específico é a sua capacidade de se transformar num "repertório de interação social" (Domingos 2009). A narrativa, forma de organização do conhecimento que beneficia da estrutura sequencial e recorrente das competições desportivas, modo de acumulação contínua de conhecimento, tem a propriedade de um material de interação (Goffman 1983: 11), dispositivo de comunicação e apresentação individual. O seu valor de uso, desigual em função dos indivíduos e grupos que a manipulam, remete para mercados de práticas contextuais. As narrativas futebolísticas participam em processos de ritualização social, vertente de uma cultura popular urbana, com uma dimensão performativa específica; são um meio de participação social e de sociabilidade e criação de laços.

O papel das narrativas futebolísticas cunhadas nacionalmente num quadro migratório, como em outros quadros históricos e sociais, extravasa a função de representação nacional que é mais visível enquanto expressão consciente de uma identidade. Os seus usos sociais quotidianos sugerem, no entanto, outras lógicas de causalidade: misturam-se com condições de existência particular, com a inserção dos indivíduos no contexto produtivo local, aspeto primordial da definição formal e informal da condição do imigrante, com a distribuição desigual de outras propriedades individuais e coletivas, como o capital educacional ou cultural. A relação da narrativa futebolística com estas condições contextuais garante-lhe determinado valor num mercado de consumos e de lazeres alargado, o que remete para a sua integração numa conceção lata de estilo de vida, eixo de uma situação social delimitada e também do modo como os indivíduos se concebem e imaginam a sua posição em determinado contexto social. Como base do estabelecimento de relações sociais, a narrativa futebolística é um recurso quotidiano com um valor variável. 


\section{COMUNIDADES EM CONSTRUÇÃO}

Em março de 2008 o presidente da República portuguesa Aníbal Cavaco Silva visitou Moçambique. A antiga colónia portuguesa é um dos países mais pobres do mundo. Os dados do relatório de 2010 que apresenta o índice de desenvolvimento humano publicado pela ONU colocavam Moçambique no $165 .^{\circ}$ lugar, num conjunto de 169 nações. O país tem taxas de mortalidade altas e uma esperança de vida reduzida, números para os quais contribuiu a prevalência de doenças como a sida e a malária. Conquistada a independência em 1975, Moçambique atravessou uma dramática guerra civil que apenas findou em 1992. Em 1990 o governo de partido único de tendência socialista deu lugar a um regime democrático, até à atualidade liderado pela Frelimo (Frente de Libertação de Moçambique). A economia centralizada passou nos anos 90 a abrir-se ao exterior, iniciando uma fase geral de liberalização e internacionalização apadrinhada e coordenada por instituições internacionais como o Banco Mundial e o Fundo Monetário Internacional. ${ }^{3}$

No site criado propositadamente para acompanhar a visita presidencial havia uma entrada dedicada à comunidade portuguesa, com os representantes da qual Cavaco Silva se encontraria. ${ }^{4}$ Como noutras viagens de Estado, o presidente português, em articulação com o Ministério dos Negócios Estrangeiros e respetiva Secretaria de Estado, esforçou-se por realçar a existência de uma comunidade de portugueses, o que provava mais uma vez a vocação diaspórica de um povo, tanta vez relacionada com esse momento fundador que foi a gesta dos "descobrimentos". Esta comunidade portuguesa, como todas as outras espalhadas pelo mundo, representava o país, promovendo a língua e as características de uma cultura nacional, tão dificilmente mensuráveis, mas que o Estado estava disposto a preservar e a reproduzir (Melo e Silva 2009: 40-41). As Comunidades Portuguesas, como notou o referido site, são "verdadeiros embaixadores de Portugal e primeiro garante da defesa e afirmação da cultura lusa além-fronteiras". ${ }^{5}$

$\mathrm{O}$ estatuto de Moçambique como ex-colónia portuguesa tornava algumas destas características "culturais lusas" menos relevantes neste processo de construção coletiva. A língua, marcador nacional por excelência, perdia relevância neste contexto onde o português, apesar de falado por uma minoria da população (Firmino 2002) era desde 1975 o idioma oficial. A língua e o passado histórico comum juntavam todos os países de uma comunidade lusófona, organizada deste 1996 na Comunidade dos Países de Língua Portuguesa (CPLP).

3 A propósito desta evolução da economia moçambicana, ver, entre outros, West (2009), Hall e Young (1997).

4 Ver < http://www.presidencia.pt/mocambique2008/?idc=175\&idi=14551 > (último acesso em $30 / 8 / 2011)$.

5 Idem. 
$\mathrm{Na}$ intervenção dirigida aos moçambicanos, Cavaco Silva resumiu a base desta relação lusófona: "Estamos unidos por laços de afeto e de proximidade histórica e cultural muito particulares, partilhamos um importante património com outros seis Estados soberanos, que é o da língua portuguesa, e queremos potenciar ainda mais esta vantagem estratégica, cada vez mais reconhecida a nível global". ${ }^{6}$ Mais tarde, já durante a estadia em Moçambique, acrescentaria: "Quando pensamos em interesses estratégicos que são comuns pensamos logo na CPLP". ${ }^{7}$

A vantagem estratégica facultada pelos insondáveis desígnios da história devia agora traduzir-se noutras áreas de atividade; segundo Cavaco Silva: "Estou empenhado, tal como as delegações que me acompanham, em contribuir para um novo ciclo de cooperação económica e empresarial entre os dois países". ${ }^{8}$ O presidente da República, como relatou a imprensa, fez-se acompanhar nesta visita por quatro ministros, dois secretários de Estado, deputados e representantes de 45 empresas, que incluíam os principais investidores portugueses em Moçambique: os bancos Millennium-BCP, CGD e BPI, a EDP e a Galp Energia, as Águas de Portugal, as construtoras Teixeira Duarte e Soares da Costa, a Visabeira, os operadores turísticos TAP, Grupos Pestana e Amorim. O investimento português em Moçambique tem crescido de forma assinalável nos últimos anos, sobretudo nos setores da banca, energia, telecomunicações, cimento e construção, distribuição de água e turismo (Matos 2009: 177). O papel estratégico da visita presidencial foi vincado pela realização de um seminário económico, promovido pela Aicep Portugal Global, Agência para o Investimento e Comércio Externo de Portugal, vocacionada para a globalização da economia portuguesa e a promoção da imagem do país, organizando campanhas de marketing internacional sob a expressão "Marca Portugal".

\section{UMA COMUNIDADE PORTUGUESA?}

Assumindo-se que a existência de uma comunidade implica a partilha por um conjunto de indivíduos de determinadas particularidades objetivas e subjetivas suficientemente relevantes para justificar a operacionalidade do próprio termo, os dados sobre os indivíduos que formavam a comunidade portuguesa em Maputo pareciam expor uma contradição entre a proclamada imagem de um grupo homogéneo unido por uma cultura nacional e a diversidade de atributos e experiências históricas que caracterizavam os seus membros. O site da presidência anunciava a presença de 11 mil portugueses em Moçambique.

6 Ver < http://www.presidencia.pt/mocambique2008/?idc $=178$ \&idi $=14245>$.

7 Ver a entrevista ao seminário moçambicano Domingo, republicada em <http://tvl.rtp.pt/noticias/ ?article $=59210$ \&visual $=3$ \&layout $=10>$.

8 Ver < http://www.presidencia.pt/mocambique2008/?idc $=178 \&$ \&idi $=14245>$. 
Mais de metade, cerca de seis mil, havia nascido no território, e a maior parte nunca terá ido a Portugal; apenas 3845 eram naturais do país. Dos restantes nacionais, destacavam-se os 547 que haviam nascido na Índia mas que possuíam passaporte português. Segundo os dados cedidos pelo Consulado Português em Maputo referentes a junho de 2006, o universo de 10.279 portugueses registado, dos quais $655 \mathrm{com}$ dupla nacionalidade, era relativamente masculinizado (56,8\%) e urbano (89\% encontrava-se em Maputo). ${ }^{9}$ Em recente e inédito artigo sobre a população portuguesa em Maputo, Elizabeth de Matos sugere que os números oficiais ficam aquém da realidade, avançando a autora com a cifra de 30 mil indivíduos (Matos 2009: 164). Algumas razões são adiantadas para explicar a discrepância. Serão sobretudo os imigrantes deslocados recentemente, em especial os beneficiários das facilidades concedidas pelas leis de abertura ao investimento estrangeiro, aqueles que maioritariamente estão inscritos no consulado. ${ }^{10}$ Outros portugueses, apesar de o Estado moçambicano o proibir, mantêm passaporte dos dois países, mas não se registaram. Por fim, haverá em Moçambique imigração constituída por indivíduos com problemas legais e criminais em Portugal, condição pouco compatível com a denúncia oficial da sua presença (Matos 2009). Incluídos ou não no número de cidadãos que se encontram nesta situação perante a lei, há em Maputo vários portugueses que vivem na margem de uma representação oficial da nacionalidade. Em 2006 conheci vários destes homens, dependentes de negócios duvidosos e com uma existência precária, muitas vezes partilhada com mulheres moçambicanas. As condições da sua vinda para Moçambique enunciavam, por si só, uma narrativa sobre a sua relação conflitual com Portugal, onde deixavam dívidas, o fantasma do desemprego ou relações familiares desestruturadas.

No universo da população que passou a ser considerada portuguesa na sequência da lei da nacionalidade aprovada depois da independência das antigas colónias nacionais, e que consagrou o critério jus sanguinis em detrimento do jus soli, 165 mil indivíduos regressaram à antiga metrópole, 20 mil permaneceram em Moçambique, rumando parte substancial dos restantes $60 \mathrm{mil}$ para a África do Sul e para a antiga Rodésia de Ian Smith, hoje Zimbabué (Matos 2009: 164). Neste contexto diverso, a separação entre os "novos" e os "velhos" portugueses em Moçambique será, como notou Elizabeth de Matos, uma das mais significativas. Entre estes últimos impera uma débil identificação com Portugal, país que em muitos casos não conhecem ou conhecem mal: consideram que Moçambique é a sua terra. Este afastamento não implica que

9 Estes números referem-se apenas aos portugueses inscritos no consulado em Maputo. Sabe-se, porém, que o outro consulado português em Moçambique, situado na cidade da Beira, tem inscritos uma percentagem muito baixa do conjunto de indivíduos residentes.

10 A Lei n. ${ }^{\circ}$ 3/93 facilitou e promoveu o investimento estrangeiro em 1993. Por sua vez, o Decreto n. ${ }^{\circ}$ 25/99, de maio de 1999, estabeleceu um novo regime de vistos para trabalhadores estrangeiros (Matos 2009: 164-165). 
a origem portuguesa e referentes de identificação nacional não sejam utilizados como elementos distintivos no interior da estrutura social local.

Os novos imigrantes chegam sobretudo por razões profissionais (Matos 2009: 166-167), viagem facilitada pelas leis de enquadramento do investimento financeiro e da circulação de trabalhadores acima mencionadas. A maior parte não tem laços anteriores e vem com contratos a termo e a ideia de permanecer apenas por uma temporada. Alguns acabam por ficar. Outros dos imigrantes mais recentes regressam da Africa do $\mathrm{Sul}^{11}$ ou do Zimbabué, locais onde a situação política e económica se lhes tornou desfavorável. Estes últimos regressam para ficar e não pensam voltar a Portugal, dado que, como os "velhos portugueses", têm menos afinidades com o país.

A população portuguesa em Moçambique está assim marcada por experiências históricas diversas, por uma relação com Portugal e Moçambique diferenciada, assente em distintas naturalidades e mobilidades geográficas, e por experiências geracionais díspares.

\section{UMA COMUNIDADE LUSÓFONA?}

A diversidade que caracteriza as experiências dos portugueses em Moçambique não invalida, no entanto, que entre portugueses e moçambicanos se produzam representações que parecem desenhar a projeção de uma comunidade. O trabalho de Elizabeth de Matos (2009), baseado num número elevado de entrevistas realizadas a portugueses e moçambicanos a viver em Moçambique, revela que ser "português" é uma condição percebida por intermédio de várias categorias, destacando-se, a este propósito, aquela que remete para o passado colonial. Os portugueses reconhecem que a relação com os moçambicanos é ainda muito influenciada pelas memórias vividas da opressão colonial, unificadas por um discurso oficial, reproduzido em discursos, pelos media e pela escola. Mas acrescentam que certa imagem negativa resulta também da sua posição profissional e social, a de uma minoria privilegiada num contexto de enorme pobreza (Matos 2009: 169). Quase metade dos portugueses entrevistados por Elizabeth de Matos afirma sentir racismo por parte dos moçambicanos (2009: 170), que, por sua vez, se queixam dos portugueses pelas mesmas razões. Apesar de reconhecerem o seu impacte na sociedade moçambicana, nomeadamente cultural (2009: 173), os moçambicanos entrevistados continuam a ver o português como o colonizador (Matos 2009). Mais do que isso, 65\% consideram que os portugueses os veem como indivíduos inferiores, reproduzindo modos de categorização que inevitavelmente relembram velhas formulações coloniais: preguiçosos, pouco inteligentes, incompetentes (2009: 174-175). Estas impressões assentam em experiências quotidianas práticas, por exemplo

11 A propósito da comunidade portuguesa na África do Sul, ver Silva (2009). 
em lojas exploradas por portugueses, mas também em observações sobre as relações utilitárias dos portugueses com as mulheres moçambicanas (2009: 174). Este facto distinguiria, aliás, o comportamento dos portugueses do de outros "brancos" em Moçambique. A autora conclui reconhecendo que entre portugueses e moçambicanos persiste um regime de separação. $\mathrm{O}$ fechamento social dos portugueses, mais evidente naqueles que chegaram há pouco tempo (2009: 17 1), reforça um tipo de representação estereotipada sobre o outro e a permanência de uma vincada desconfiança.

A fragilidade das análises que tendem a reduzir as relações de poder a uma dualidade nacional, que quase sugere uma espécie de racismo intrínseco, é percetível tanto nas análises que confinam as relações de poder à expressão de um confronto entre comunidades nacionais, como naquelas que, eliminando o poder da equação, sustentam a agregação daquelas unidades comunitárias numa nova unidade cultural, base de uma comunidade transnacional. Em Moçambique, a condição nacional, forma de nomeação corrente, sintetiza complexas relações de poder. Os portugueses foram os autores visíveis e nomeáveis de um sistema de dominação que lhes concedia por meios legais e ilegais uma supremacia sobre as populações locais. A experiência colonial de desigualdade, além de permanecer em sentimentos e discursos contemporâneos, parece confirmar-se pela situação atual da maioria dos portugueses na sociedade moçambicana.

Os dados sobre a inserção profissional da população portuguesa denunciam uma posição social relativamente confinada. Entre trabalhadores qualificados do setor da prestação de serviços e na indústria até aos mais recentes trabalhadores por conta própria, em especial nas áreas do comércio, transportes rodoviários, hotelaria, restauração, pescas e atividades ligadas à agricultura, os portugueses vivem em Moçambique, de forma genérica, uma situação privilegiada. ${ }^{12}$ Dos 10.279 recenseados no consulado de Maputo em 2006, 867 eram menores em idade escolar, 1374 eram estudantes e 211 eram reformados. Na população ativa havia 1287 indivíduos na categoria de "profissões científicas técnicas e liberais", 847 na de "pessoal do comércio e vendedores" e 157 desempenhavam tarefas administrativas. ${ }^{13}$ Significativamente, não havia registo de portugueses na categoria de "pessoal dos serviços de proteção e segurança, pessoais e domésticos”, existiam muito poucos a exercer profissões operárias, apenas oito indivíduos na categoria de "trabalhadores de produção e indústrias extrativas, transformadoras e condutores de máquinas" e apenas 75 em atividades de "agricultura e trabalhos agrícolas".

12 Todos os dados apresentados neste parágrafo foram fornecidos pelo Consulado Português em Maputo e são relativos ao ano de 2006.

13 A imprecisa estatística agrupa em "trabalhos não classificados" 2900 portugueses, o que deve incluir um conjunto grande de atividades. 
Esta situação sugere uma posição social dominante e a confirmação de algumas das representações herdadas do tempo colonial. As representações sobre "o português" remetem para uma situação de privilégio, assente no opressor passado colonial, numa situação atual de minoria abastada e na sua condição de "branco", expressão fenotípica da hegemonia de relações de poder antigas e sinal da permanência da "raça" como elemento de explicitação da lógica de estratificação. Outras variáveis de estatuto social podiam ser avançadas no contexto destas representações dominantes, revelando distinções mais finas, complexificando, mas não anulando, a força destas noções dominantes. Estas representações hegemónicas traduzem-se de forma particular nas interações quotidianas, sobretudo porque apenas em espaços de partilha determinados por um fechamento social a normal assimetria das relações de poder entre moçambicanos e portugueses é atenuada. Desta forma, impõe-se em termos gerais, em espaços públicos ou privados, uma ordem da interação penalizadora para os moçambicanos, formalmente injusta, produtora de inseguranças, para a existência da qual os traços fenotípicos continuam a ser elementos preponderantes. Esta subordinação pública é muitas vezes invertida no contexto do que Erving Goffman designou como as regiões dos bastidores (Goffman 1993 [1959]), ou no que James Scott nomeou hidden transcripts (Scott 1990), espaços sociais protegidos onde finalmente se tornava possível comentar crítica e abertamente, sem penalizações, um sistema de relações de poder. Para quebrar a ontologização nacional sugerida pela análise, é de assinalar que as mesmas lógicas se manifestam em contextos de relações de poder muito assimétricas em que os portugueses não estão presentes. É assim, em situações públicas e privadas, nas relações entre os moçambicanos mais pobres - quase todos os moçambicanos - e outros estrangeiros, brancos e abastados, como também o é entre aqueles moçambicanos e as novas classes dominantes locais, negras, mestiças e sempre abastadas, que reproduzem práticas socialmente codificadas estruturadoras das relações de poder.

\section{UM ESTILO DE VIDA NACIONAL?}

A posição social dos portugueses em Maputo reflete-se nos seus estilos de vida e em práticas de fechamento que apenas parcialmente podem ser atribuídas a uma partilha nacional. Pedro Soares dos Santos, administrador da Jerónimo Martins, proprietária de várias redes de grande distribuição, entre as quais os supermercados Pingo Doce, dizia recentemente que o seu grupo não investia em Angola e Moçambique, sobretudo em Moçambique, porque nestes países não havia consumidores (Expresso, caderno Economia, 13/12/2010, p. 14). Com esta afirmação assinalava a quantidade insuficiente do tipo de consumidor necessário para viabilizar uma rede de retalho com determinadas características. A maior parte da população de Maputo abastece-se em 
mercados locais, mais ou menos informais, que caracterizam a cidade, em especial os seus subúrbios. Por lá circulam todo o tipo de produtos, mas sobretudo os de primeira necessidade. É ainda nestes contextos de consumo que se reproduzem inúmeras práticas de encontro e de lazer, base de determinados estilos de vida. Os consumos e estilos de vida da grande maioria dos portugueses em Maputo, refletindo a sua posição social, contrastam de forma radical com os hábitos e as rotinas atrás definidos. Grande parte desta população habita os bairros privilegiados concentrados na parte este de Maputo: Polana, Sommerchild e o mais central Bairro da Coop. Nesses contextos, coabitam com outros membros desta classe dominante outros estrangeiros e a florescente classe alta moçambicana, produto das prioridades económicas do país. Os portugueses frequentam habitualmente espaços públicos situados na mesma área ou na parte mais cara da baixa da cidade. É fácil encontrá-los em restaurantes dispendiosos para o moçambicano médio onde a proporção de indivíduos brancos aumenta significativamente, como são os casos do Monte Alentejano, a Taverna, a Cristal, o Piri-Piri, o Costa do Sol, o Escorpião ou o Cegonha, ou em cafés como o Nautilus ou o Surf, ou em locais de convívio relativamente confinados como o Jardim dos Namorados, ou em bares como o Kampfumo, na estação de caminho-de-ferro, no Eagles, no Rua d'Arte ou no Mundo's, ou ainda em clubes como o Náutico e o Naval.

Nos que chegaram mais recentemente nota-se uma maior distância em relação aos hábitos de consumo dos moçambicanos. Muitos destes portugueses, apesar do preço mais elevado, preferem comprar produtos nacionais nos supermercados e muito raramente se arriscam nos mercados de rua. Mesmo nos supermercados prefere-se Luso, Mimosa ou Quinta da Aveleda ao invés de marcas locais ou sul-africanas, como Namaacha, Clover ou Nederburg. A maioria desta população viaja em transporte particular ou táxi, evitando a rede de "chapas", transportes públicos explorados por privados que atravessam a cidade. Os seus filhos são educados em escolas privadas, destacando-se a este propósito a Escola Portuguesa em Maputo, criada em 1999 no âmbito de um acordo de cooperação. Quando necessitam de assistência médica dirigem-se a clínicas privadas; quando o caso é mais grave rumam até à vizinha África do Sul. Como é usual nas classes média e alta locais, a maioria dos portugueses tem empregadas domésticas e "bábás" que limpam, cozinham e tomam conta das crianças e quase sempre contratam serviços de segurança, segmentos da oferta de emprego cruciais para a grande reserva de mão de obra suburbana.

A diversidade histórica de experiências da população portuguesa junta-se ao seu genérico confinamento de classe como fatores de explicação do reduzido número de lugares de encontro comunitário institucionalizado. A Confraria do Bacalhau, espaço reservado a sócios, é um dos seus poucos lugares de encontro. Em Maputo só existe mais uma associação de portugueses, a 
Associação Portuguesa de Moçambique, com uma atividade pouco saliente. ${ }^{14}$ Não se reproduz em Maputo a experiência de constituição de locais de encontro coletivo que caracterizou a imigração portuguesa (Melo e Silva 2009), bem com o quotidiano dos colonos na então cidade de Lourenço Marques (Domingos 2009). Imigrantes e colonos em processo de mobilidade trouxeram hábitos importados dos contextos de origem, valorizados enquanto estratégias de sobrevivência e de equilíbrio existencial.

Como evidenciam os artigos deste dossiê, o associativismo estabelece-se também como um dos eixos de reprodução de uma narrativa futebolística portuguesa em várias partes do mundo, tal como havia sucedido em Moçambique durante o período colonial. Os novos imigrantes portugueses em Maputo chegam, em termos genéricos, ou com pouca experiência associativa, ou com uma experiência associativa distinta. A sua adaptação ao novo contexto, bem como aliás a sua vida no local de origem, dependem menos dos recursos e da ativação de uma rede de relações comunitárias centrada em associações de índole nacional, regional, desportivas ou recreativas, do que de outro tipo de capitais, decorrente da posse de qualificações educacionais e sobretudo de contactos profissionais estabelecidos já em Portugal. A este fraco associativismo acrescenta-se a quase invisibilidade dos momentos de celebração nacional. Só o 10 de Junho, oficialmente organizado pelas autoridades portuguesas locais, merece uma comemoração. O Dia de Portugal inclui uma cerimónia organizada pela embaixada e tem normalmente como ponto alto um concerto de um artista português. Em 2006, quando me encontrava em Maputo, a artista convidada foi a fadista Mariza. Esta comemoração foi oferecida à comunidade portuguesa, dir-se-ia aos seus representantes mais notáveis, mas também às "forças locais" da cidade. O preço do bilhete do espetáculo era de 950 mil meticais, ou seja, na altura, quase 35 euros, três quartos do salário mínimo nacional, mais ou menos o que recebe por mês uma empregada doméstica por trabalhar nove horas por dia, de segunda a sábado. À parte destas comemorações, datas como o 25 de Abril e o 5 de Outubro passam despercebidas.

Estas formas e estilos de vida tendem a criar um distanciamento entre os portugueses e a maior parte da população local. No caso daqueles que chegaram há menos tempo, a própria fonética da língua portuguesa acentua a já evidente diferença social. O fechamento social da maioria dos portugueses - dir-se-iam os pequenos fechamentos sociais, dada a sua fraca dinâmica coletiva - é marcado por um conjunto de práticas em relação ao trabalho, à educação e à saúde, aos percursos urbanos e aos lazeres, resultantes de um lugar de classe que, em determinadas ocasiões, se manifesta pela demarcação de uma pertença nacional. Nestes contextos, a identificação nacional atua como um meio de 
distinção social. Questionemos, pois, o papel do futebol nestas estratégias de fechamento e relacionamento sociais.

\section{A NARRATIVA DO FUTEBOL PORTUGUÊS COMO FORMA DE CONTRASTE SOCIAL}

O aspeto mais relevante dos usos sociais da narrativa do futebol português em Maputo é sem dúvida o facto de não serem os portugueses aqueles que mais intensamente exploram a sua manipulação quotidiana. Se o futebol é um dos sinais mais evidentes de uma presença atualizada de Portugal na capital de Moçambique, perante o desinteresse geral sobre os assuntos da antiga colónia, isso deve-se aos adeptos moçambicanos (Domingos 2005-2006). Tal fenómeno assenta fundamentalmente na identificação local com os clubes portugueses, núcleos fundamentais da reprodução regular desta narrativa em Maputo, eixos de memórias e de acumulação de conhecimentos. A vitalidade revelada pela narrativa do futebol português no contexto da cultura popular urbana em Maputo é reconhecível pelo acompanhamento prestado pelos media: as transmissões semanais de jogos portugueses pela televisão pública moçambicana (TVM), acrescentadas aos jogos mostrados pela RTP África, os relatos na rádio, as notícias nos jornais, a circulação de jornais desportivos entre os moçambicanos - ao contrário da outra imprensa portuguesa e apesar do seu preço elevado. Nas ruas de Maputo é comum observar indivíduos ostentando as camisolas dos clubes portugueses. Quando o Benfica visitou Moçambique em 2006, as manifestações públicas, no aeroporto, nas ruas, nas escolas, no estádio, assinalaram a extraordinária popularidade do clube português (Domingos 2005-2006).

Reduzida à sua função de instrumento de representação comunitária, a narrativa futebolística portuguesa parece comprovar, pela sua pujante presença em Maputo, a persistência de uma presença cultural portuguesa, herança do período colonial, elegível como símbolo de uma condição lusófona. Noutra perspetiva, como algumas opiniões assinalaram, ${ }^{15}$ o apreço popular pelas ocorrências da narrativa do futebol português constitui-se como um sinal de neocolonialismo e de falta de autoestima dos habitantes da nova nação, que passivamente aceitam esta forma de aculturação. Estas interpretações ignoram, no entanto, as utilizações desta forma social específica enquanto eixo de práticas quotidianas e o seu poder na criação de laços sociais, de rotinas e de performances retóricas e corporais (Domingos 2009). Durante o período colonial, a hegemonia da narrativa metropolitana na cultura popular da colónia de Moçambique, não apenas entre os colonos e seus descendentes, deveu-se 
ao seu papel particular na formação de laços sociais que acompanhou o processo de estruturação urbana realizado num meio colonial em transformação (Domingos 2005-2006).

Passados 31 anos sobre o fim do colonialismo em Moçambique, o meu domínio desta narrativa permitiu, em inúmeras interações, comprovar o modo como inúmeros habitantes da cidade de Maputo a manipulam com agilidade. Foi assim em cafés, em conversas com vendedores, em lojas, em mercados de rua, com jovens estudantes, com velhos habitantes da cidade. A narrativa futebolística portuguesa revela-se um idioma social vivo, usado nos tempos de lazer, mas também em contextos laborais, familiares ou escolares. ${ }^{16}$ Tal como a língua portuguesa em Maputo, utilizada como fim prático de comunicação, e estando sujeita a um mercado linguístico que a coloca em competição com outras línguas e idiomas, se submete aos usos que dela fazem, sendo assim apropriada e reorganizada, também a narrativa futebolística portuguesa, idioma social, sobrevive pelos seus usos práticos, sendo objeto de inúmeras apropriações. As utilizações quotidianas das narrativas futebolísticas portuguesas por parte dos moçambicanos convivem com as representações negativas da população do antigo colonizador. Quando se identificam com os clubes portugueses, eixos a partir dos quais os indivíduos se situam em relação à narrativa e núcleo das suas retóricas e posições, os moçambicanos não parecem imaginar um referente nacional. Desnacionalizados, estes clubes parecem afirmar-se simultaneamente como entidades supranacionais, pertencentes a uma cultura popular global. Muitos adeptos moçambicanos conhecem as ocorrências de diversos campeonatos de futebol europeus, o que demonstra a circulação transnacional das narrativas futebolísticas. $\mathrm{O}$ mesmo processo de mobilidade do conhecimento é visível noutras dimensões de uma cultura popular globalizada, desde as novelas brasileiras à música ou ao cinema americanos, mas também no contexto de globalizações mais locais, decorrentes, por exemplo, da influência da cultura popular sul-africana ou da importância, localmente significativa, do cinema indiano. Como outros elementos de uma cultura popular globalizada, o futebol português, sedimentado nas preferências clubistas locais desde o momento em que alguns naturais de Moçambique se destacaram no então campeonato metropolitano, serve as práticas e a imaginação dos adeptos moçambicanos.

Em suma, os significados criados por esta narrativa, decorrentes de usos que se expressam em manifestações de aprovação ou desaprovação, argumentos, opiniões e emoções, são, em grande medida, independentes dos referentes nacionais aos quais estão associados e relativos a factos e ocorrências inerentes ao universo intrínseco da narrativa, da sua ordem factual, sempre disputada

16 O antropólogo John Peel utilizou o termo social idiom para caracterizar a função das religiões monoteístas na África colonial (Peel 1984: 154). 
retoricamente. A faculdade representativa da narrativa não desaparece, apenas se complexifica. O efeito de representação depende do contexto de interação e performance, o que remete para uma diversidade de ordens sociais que se encontram bastante para lá de uma constante remissão para o imaginário nacional. A interpretação dos usos concedidos pelos moçambicanos à narrativa futebolística portuguesa, contrariando explicações fundadas na simples representação nacional, pode enveredar, no entanto, por uma uniformização da condição de "moçambicano". Para lá da assinalada hegemonia masculina, quem são os moçambicanos que mais manipulam esta forma social específica? E por que razão o jogo parece ser mais importante para eles do que para a população portuguesa em Maputo?

\section{NARRATIVAS FUTEBOLÍSTICAS E MODERNIDADE}

Para se avaliar o peso da narrativa do futebol português no contexto da formação de estilos de vida em Maputo na atualidade é necessário examinar mais atentamente as suas condições sociais e históricas de produção. No contexto colonial, o surgimento de práticas e consumos desportivos modernos assumia-se com um elemento de uma cultura popular urbana e um símbolo de uma era moderna. ${ }^{17}$ Foi assim que, mesmo sob um sistema de discriminação institucionalizado (Zamparoni 1998), as populações dos subúrbios de Lourenço Marques, de modo mais ou menos organizado, desenvolveram autonomamente os seus clubes e competições. Por outro lado, o processo de desportivização em Moçambique, em diálogo com as transformações históricas no sistema colonial, deu origem a um conjunto de dinâmicas bastante particulares, nomeadamente criando um espaço de mobilidade social para atletas do subúrbio pobre. Esta possibilidade foi reforçada pelas conquistas dos pioneiros deste processo - Matateu, Coluna, Hilário ou Eusébio -, que rapidamente se tornaram, primeiro, no mundo do futebol dos colonos, depois, nos clubes metropolitanos, vedetas de um espetáculo fortemente mediatizado, figuras de uma cultura popular alargada. A sua participação destacada na então narrativa metropolitana reforçou a disseminação de um conhecimento específico sobre os clubes, os jogadores, os resultados e as performances. Tal informação constituiu-se como matéria de rituais sociais reproduzidos entre os habitantes da cidade. Apesar de o desporto se ter instituído em Moçambique como um instrumento de múltiplas discriminações, vincando o desígnio do sistema colonial (Domingos 2010), a lógica profissionalizante inerente ao processo de desportivização criou o seu espaço de possibilidades objetivas, ampliado pelo contexto do colonialismo tardio, que se traduziu de forma indelével na cultura popular urbana de Maputo. Os usos da narrativa desempenhavam um papel de 
criação de laços sociais, num contexto de multiplicação das interdependências, correlativo de uma maior especialização social do trabalho, do conhecimento e das práticas de lazer.

A formação de narrativas futebolísticas durante o período colonial expressava o advento de uma condição urbana. À margem da sociedade colona, foi entre as populações mais urbanizadas - as que viviam próximas do centro, aquelas cujo quotidiano se relacionava de modo mais notório com um mercado de trabalho formal, os que tinham maior mobilidade urbana, índices de educação mais elevados, acesso à informação e contacto regular com os colonos - que a narrativa metropolitana se difundiu. A importância da narrativa metropolitana para estes estratos da população é comparável à centralidade adquirida pelos usos de outros elementos de uma condição urbana em constituição, que expressavam modos de adaptação, manipulação e apropriação, e não um simples mimetismo, e que se traduziam em consumos, práticas de lazer e formas de vestir diversos. ${ }^{18}$ Os usos da narrativa metropolitana constituíram-se como uma dimensão distintiva do estilo de vida urbano de certa classe de habitantes da cidade de Maputo. No contexto da sociedade colonial, o seu valor, como elemento de distinção, não se comparava a outros consumos e práticas. As sociabilidades da elite colona assentaram na partilha de lazeres específicos, entre os quais se encontravam a prática de desportos como a vela ou o ténis. Para alguns elementos de camadas da pequena burguesia africana, numericamente residuais, o futebol era preterido a práticas desportivas consideradas mais civilizadoras, como a ginástica (Domingos 2009: 123-124). Ainda assim, no seio da população que ia progressivamente habitando a cidade, entre a maioria dos colonos e parte da população suburbana, o futebol estabeleceu-se como um esteio crucial da sua experiência urbana.

Entre os grupos que ganharam uma preponderância social, política e económica após a independência de Moçambique, precisamente entre camadas urbanas cujos limites não são fáceis de definir com precisão, encontravam-se muitos indivíduos para quem o futebol era uma presença regular na sua vida quotidiana; muitos indivíduos conhecedores da narrativa do futebol metropolitano e que iriam continuar a reproduzi-la, embora ela agora fosse "portuguesa". À semelhança de outros hábitos e lazeres típicos da vida urbana destes estratos da população da agora cidade de Maputo, o uso da narrativa futebolística permaneceu. Esta, como outras permanências, tendem a ser marginalizadas pelas interpretações que centram os regimes de causalidade dentro das fronteiras da história política. A identificação com a narrativa futebolística portuguesa não emanava de uma imaginação nacional ou imperial, pois a grande maioria desta população saudou o fim do colonialismo, mas dos vínculos emocionais 
e práticos a clubes, jogadores, jogos e a toda uma memória social incorporada (Connerton 1999: 4-5), traduzida no quotidiano urbano em múltiplas interações diárias que representavam e simbolizavam o advento de uma condição moderna, elemento valorizado de determinado estilo de vida, dimensão de um habitus urbano. Na cidade, o domínio da narrativa do futebol português tem a faculdade de criar um contraste entre as vivências dos estratos da população que a utilizam e, não tanto a maioria da população rural, mas sobretudo as populações suburbanas que mantêm hábitos de vida mais influenciados pela sua origem rural.

No quotidiano da maioria da população portuguesa em Maputo, o consumo do futebol exerce um papel marginal na consolidação de um estilo de vida cujas fronteiras são delimitadas por outros hábitos, também definidores de uma condição urbana, mas bastante mais restrita. O futebol não é condição de um fechamento social, fenómeno em primeiro lugar dependente das práticas, assinaladas anteriormente, que delimitam o estilo de vida de uma classe privilegiada.

\section{O ELEMENTO OCASIONAL DA NARRATIVA PORTUGUESA: A SELEÇÃO NACIONAL COMO ELEMENTO DE CONTRASTE}

A mesma lógica de diferenciação atrás descrita foi visível num contexto de consumo desportivo que, à partida, seria bastante mais indicado para demarcar a representação nacional. Nos casos das grandes competições internacionais de futebol, campeonatos europeus e mundiais, a faculdade de representação nacional inerente à narrativa desportiva destaca-se, sem prejuízo dos seus usos enquanto repertório da interação. Durante a realização do Mundial da Alemanha em 2006 e do Euro 2008, disputado na Suíça e na Áustria, notou-se uma maior dinamização dos portugueses em Maputo. Em alguns contextos, como no jogo entre Portugal e Angola, na abertura do Mundial, adeptos portugueses juntaram-se no Eagles, bar situado na baixa, propriedade de um português, munidos de camisolas, bandeiras e cachecóis. Por altura do Europeu, na cervejaria Cristal durante o encontro com a República Checa, a comunidade estava ainda mais demarcada. Todo o espaço assinalava a presença de um conjunto nacional: multiplicaram-se as bandeiras, os cachecóis e os equipamentos da seleção, num ambiente festivo. Os portugueses viam o jogo nas mesas reservadas e, desde o passeio do lado de fora, dezenas de moçambicanos olhavam para o ecrã da Cristal. Este tipo de manifestação pública foi, no entanto, menos ocasional. Na maior parte dos casos, os portugueses que decidiam ver o jogo fora de casa partilharam os espaços com os outros clientes, apresentando poucos símbolos identificadores da sua condição nacional. Foi assim no Jardim dos Namorados, situado na Polana, aquando da vitória de Portugal sobre a Holanda nos oitavos de final do mundial, ou no restaurante Mundo's, 
na ronda seguinte, contra a Inglaterra. O espaço privado parecia, no entanto, ser o local preferido para os portugueses observarem os jogos, quase sempre em reuniões de amigos, como sucedeu no Europeu de 2008 numa residência na zona da Polana, onde 20 portugueses, trabalhadores da embaixada, da banca e empresários, mas também alguns colegas de trabalho moçambicanos, se juntaram para o jogo entre Portugal e a Turquia. Apesar de o futebol ser na ocasião o motivo do encontro, estes grupos de amigos já se reuniam regulamente noutras ocasiões. Os jogos da seleção pareciam ser momentos de celebração de sociabilidades já estabelecidas, promovidas por amigos, colegas de trabalho, familiares, e não para mobilizações coletivas fundadas na identidade nacional ou na partilha regular dos usos da narrativa futebolística portuguesa, o que revela o seu valor diminuto no quadro das relações sociais.

\section{UMA NARRATIVA DISPUTADA}

Se mesmo em circunstâncias muito mediatizadas, em que o futebol servia de forma direta a representação nacional, não se viu desenhar em Maputo uma comunidade portuguesa, interessava questionar o modo como a narrativa futebolística proporcionava determinadas representações aos adeptos moçambicanos. No dia da meia-final do campeonato do Mundo de 2006, a propósito do jogo entre Portugal e França, o jornal Notícias publicava um grande anúncio do Banco de Desenvolvimento e Comércio de Moçambique e da Moçambique, Companhia de Seguros. Ambas as empresas eram propriedade do banco português Montepio Geral. No referido anúncio afirmava-se:

"Esta noite os nossos corações vão bater forte em simultâneo. Não foi Moçambique. Ficámos muito tristes. Depois queríamos Angola. Brasil, Portugal. Todos nas meias. Não aconteceu. Ficou Portugal a representar mais de 230 milhões de falantes de língua portuguesa, onde nos incluímos nós, moçambicanos. Agora vivemos um sonho. Um sonho do qual não queremos acordar. Até os grandes Eusébio e Coluna dizem que é desta. Esta noite a seleção portuguesa não vai parar. Os nossos corações vão sofrer e bater forte em simultâneo" (Notícias 5/7/2006: 12).

O anúncio assumia uma preferência coletiva dos jovens moçambicanos pelos países lusófonos. O "nós lusitano", que reproduzia mais uma vez os usos de uma retórica culturalista para perseguir objetivos de índole económica, ${ }^{19}$ estava longe, no entanto, de representar qualquer unanimidade. Uma carta de

19 A venda da companhia, pouco tempo depois, a um banco sul-africano, o First National Bank, provava que estes objetivos económicos eram bem mais precários que a pretensa substância cultural anunciada pela retórica publicitária. 
um leitor do Notícias, Feliciano Bartolomeu Chilengue, relatava a sua experiência numa das praças da cidade onde o município havia colocado ecrãs gigantes. O cenário enunciava uma situação onde "muitos não sabiam a quem apoiar, dados os laços de irmandade que nos unem àqueles dois países, apesar de sermos de continentes diferentes" (Notícias, 19/6/2006, p. 15). O leitor criticava aqueles que festejaram a derrota da seleção africana, justificando-o com "a rivalidade entre os dois povos (moçambicano e angolano)". A sua perspetiva era evidente: "Se for para apoiar as seleções africanas devíamos apoiar também Angola, como as outras, que isso vai dignificar o futebol do continente negro" (Notícias, 19/6/2006, p. 15). O apoio às equipas africanas durante o Mundial de 2006 em Maputo foi evidente na opinião pública e sobretudo na opinião publicada. Quando o Gana conseguiu passar à segunda fase da prova, o Notícias de Maputo escreveu "Gana coloca África nos oitavos de final" (Notícias, 23/6/2006, p. 26). A imaginação de um continente afirmou-se em inúmeros momentos em conjunto com uma ideia de negritude. As equipas da África "negra” eram eleitas em relação às do norte de África, embora estas últimas fossem preferidas, de forma genérica, às de outros continentes. Este fator criava também uma representação desterritorializada, já que a presença de atletas com origem na chamada África negra em equipas não africanas acabava por se tornar num critério de apreciação positiva dessas equipas, como foi visível no apoio generalizado à equipa da França, expressão fenotípica da história colonial do país, na final contra a Itália. Tal apoio culminou com a interpretação compreensiva da famosa agressão do francês Zidane ao defesa italiano Materrazzi, imediatamente justificada, em mensagens de telemóvel que circularam poucos minutos depois do acontecimento, como uma razoável defesa da honra.

Era evidente que, por detrás destas representações dos vínculos continentais e "raciais", existia uma análise, mais ou menos elaborada, das relações de poder, que quase sempre se repercutia no apoio aos fracos contra os fortes. Quando o Gana se encontrou com o Brasil nos oitavos de final da prova o Notícias anunciava a "África unida contra o Brasil” (Notícias, 27/6/2006, p. 22). A seleção brasileira, equipa muito apoiada em Maputo, foi preterida por também representar o poder no futebol. O discurso sobre o poder era quase sempre enunciado por intermédio de opiniões sobre as arbitragens, acusadas de deliberadamente prejudicarem os mais fracos, em especial as equipas africanas. O jogo de representações era bastante mais complexo do que o anúncio lusofonista da companhia de seguros Moçambique e do BDC parecia fazer crer.

O peso da representação de comunidades nacionais, continentais ou linguísticas, eivadas de discursos sobre o poder, nos usos das narrativas futebolísticas durante competições internacionais apresentava, porém, os seus limites. Sob o discurso das nações e das pertenças, os adeptos usavam constantemente argumentos de ordem estética e técnica para suportarem as suas preferências. 
A atitude militante convivia com o reconhecimento do mérito e a consagração da autonomia estética do próprio jogo. A preferência generalizada pela equipa francesa em detrimento da italiana não revelava apenas a força da negritude, mas também a importância do desempenho. Critérios semelhantes justificaram, na noite do jogo entre Brasil e França, a inversão das preferências das dezenas de pessoas que se reuniram no Jardim dos Namorados, convencidas pela "arte do futebol" demonstrada pela equipa francesa e em especial por Zidane, o seu número dez. Os usos da narrativa futebolística revelavam novamente um mundo de rituais sociais, de performances retóricas e argumentativas que juntavam opiniões sobre o mundo a interpretações sobre o jogo.

\section{CONCLUSÃO}

A proliferação de um discurso legitimador da existência de um conjunto de comunidades contribui para ocultar a lógica das ações, práticas e representações das populações que são inseridas dentro destes todos comunitários. A construção destas comunidades, promovida institucionalmente, realiza uma dupla ocultação. Por um lado, esquecendo a história, reifica e reproduz, através de um processo de eufemização, categorias que recuperam modelos de construção nacional e imperial. Por outro lado, oculta a relação dos indivíduos com as estruturas sociais onde se encontram inseridos e que se traduzem pela diversidade de posições na esfera das relações de produção, pela diversidade de posse de capitais culturais e educativos e pelas relações destes fatores com identidades de género, regionais, etc. Transforma-se a emigração económica em diáspora cultural e o sistema de dominação colonial em herança cultural. No quadro de um discurso culturalista, a história, a nação e as comunidades lusófonas surgem como as oportunidades que justificam a existência de planos estratégicos de natureza económica. Durante o Estado Novo, este discurso justificou a manutenção da força colonial portuguesa em África, projeto mais amplo de evidentes contornos económicos (Alexandre 1979; Clarence-Smith 1985), fundado na exploração do trabalho indígena e na cobrança de impostos, que se refletiu na formação de sociedades radicalmente desiguais e com uma estratificação social racializada.

O estudo de um consumo cultural específico organizado por uma narrativa futebolística portuguesa, elemento de uma cultura popular urbana com um significado particular na história de Moçambique, possibilita desafiar estas construções culturais comunitárias. O significado histórico desta narrativa, apesar do seu referente nacional, empossa-a como um elemento de uma experiência urbana dotada de uma autonomia funcional, apropriada por indivíduos colocados em contextos sociais específicos que a usam como estratégia de relacionamento quotidiano. A necessidade de "desnacionalização" desta narrativa futebolística é comprovada pelo papel acessório que ela desempenha na vida 
da maioria da população portuguesa em Maputo, cujos estilos de vida, recorrendo por vezes às pertenças nacionais como forma de demarcação social, são marcados por um fechamento assente em vivências típicas de uma classe privilegiada. Noutro sentido, o uso destas narrativas por estratos da população moçambicana reproduz uma experiência histórica de modernidade cuja base se situa no período colonial e que, pelas faculdades atrás apontadas, se mantém como uma estrutura de relação quotidiana.

\section{BIBLIOGRAFIA}

ALEXANDre, Valentim, 1979, Origens do Colonialismo Português Moderno. Lisboa, Sá da Costa.

APPADURAI, Arjun, 1996, Dimensões Globais da Globalização. Lisboa, Teorema.

ARMSTRONG, Gary, e Richard GIULIANOTTI (orgs.), 1999, Football Cultures and Identities. Londres, Macmillan Press.

- (orgs.), 2001, Fear and Loathing in World Football. Oxford, Berg.

- (orgs.), 2004, Football in Africa, Conflict, Conciliation and Community. Hampshire, Palgrave.

BALE, John, e M. CRONIN (orgs.), 2003, Sport and Postcolonialism. Oxford, Berg.

BARBER, Karin (org.), 1997, African Popular Culture. Indiana, James Currey.

BERGER, Peter, e Thomas LUCKMANN, 1967, The Social Construction of Reality. Nova Iorque, Anchor Books.

CLARENCE-SMITH, Gervase, 1985, The Third Portuguese Empire (1825-1975): A Study in Economic Imperialism. Manchester, Manchester University Press.

CONNERTON, Paul, 1999, Como as Sociedades Recordam. Oeiras, Celta.

COPLAN, David, 1979, "The African musician and the development of the Johannesburg entertainment industry, 1900-1960", Journal of Southern African Studies, 5 (2): 135-164.

DOMINGOS, Nuno, 2005-2006, "O futebol português em Moçambique como memória social”, Cadernos de Estudos Africanos, 9/10: 113-128.

— — 2006, "Futebol e colonialismo, dominação e apropriação: sobre o caso moçambicano", Análise Social, XLI (179): 397-416.

—, 2009, Football in Colonial Lourenço Marques: Bodily Practices and Social Rituals. Londres, School of Oriental and African Studies, University of London, dissertação de doutoramento.

— 2010, "As políticas desportivas do estado colonial em Moçambique”, Lusotopie, XVI (2): 83-104.

DOMINGOS, Nuno, e Rahul KUMAR, 2006, "A grande narrativa futebolística”, em Diogo Ramada Curto (org.), Sociologia da Leitura em Portugal no Século XX. Lisboa, Fundação Calouste Gulbenkian, 575-638. 
ELIAS, Norbert, 1992, "A génese do desporto: um problema sociológico", em Norbert Elias, A Busca da Excitação. Lisboa, Difel, 187-215.

FAIR, Laura, 2001, Pastimes and Politics, Culture, Community, and Identity in Post-Abolition Urban Zanzibar - 1890-1945. Oxford, James Currey.

FIRMINO, Gregório, 2002, A “Questão Linguística” na África Pós-Colonial: O Caso do Português e das Linguas Autóctones em Moçambique. Maputo, PróMédia.

GOFFMAN, Erving, 1983, "The interaction order", American Sociological Review, 48 (1): $1-17$.

—., 1993 [1959], A Apresentação do Eu na Vida de Todos os Dias. Lisboa, Relógio d'Água.

HALL, Margaret, e Tom YOUNG, 1997, Confronting Leviathan: Mozambique since Independence. Londres, Hurst.

MacCLANCY, Jeremy (org.), 1996, Sport, Identity and Ethnicity. Oxford, Berg.

MANGAN, J.A., e A. RITCHIE (orgs.), 2004, Ethnicity, Sport, Identity: Struggles for Status. Londres, Frank Cass.

MARTIN, Phyllis M., 1995, Leisure and Society in Colonial Brazzaville. Cambridge, Cambridge University Press.

MATOS, Elizabeth D., 2009, "Post-colonial Portuguese migration to Mozambique: an examination of causes, effects and future implications for development", International Migration, 47 (3): 157-184.

MELO, Daniel, e Eduardo Caetano da SILVA (orgs.), 2009, Construção da Nação e Associativismo na Emigração Portuguesa. Lisboa, Imprensa de Ciências Sociais.

PEEL, J.D. Y., 1984, "Social and cultural change", em The Cambridge History of Africa, vol. 8. Cambridge, Cambridge University Press, 142-191.

SCOTT, James, 1990, Domination and the Arts of Resistance, Hidden Transcripts. New Haven, Yale University.

SILVA, Marcos Toffoli da, 2009, "Entre vítimas e algozes: dilemas da 'comunidade portuguesa' na África do Sul pós-apartheid”, em Daniel Melo e Eduardo Caetano da Silva (orgs.), Construção da Nação e Associativismo na Emigração Portuguesa. Lisboa, Imprensa de Ciências Sociais, 273-301.

WEST, Harry, 2009, Kupilikula: O Poder e o Invisível em Mueda. Lisboa, Imprensa de Ciências Sociais.

ZAMPARONI, Valdemir, 1998, Entre Narros e Mulungos: Colonialismo e Paisagem Social em Lourenço Marques, c. 1890 - c. 1940. São Paulo, Faculdade de Filosofia, Letras e Ciências Humanas da Universidade de São Paulo, dissertação de doutoramento em História Social. 